\title{
Statistical and Microstructural Analyses of Al-C-Cu Composites Synthesized Using the State Solid Route
}

\author{
Audel Santos Beltrán ${ }^{1, *}$, Verónica Gallegos Orozco ${ }^{1}$, Miriam Santos Beltrán ${ }^{1}$, Cynthia Gómez Esparza ${ }^{2}$, \\ Iza Ronquillo Ornelas ${ }^{1}{ }^{\mathbb{D}}$, Carmen Gallegos Orozco ${ }^{3}$, Luz. E. Ledezma Beng ${ }^{3}$ and Roberto Martínez Sánchez ${ }^{2} \mathbb{C D}$ \\ 1 Departamento de Nanotecnología, Universidad Tecnológica de Chihuahua Sur, Km. 3.5 Carr., \\ Chihuahua a Aldama, Chihuahua 31313, Mexico; vgallegos@utchsur.edu.mx (V.G.O.); \\ msantos@utchsur.edu.mx (M.S.B.); ironquillo@utchsur.edu.mx (I.R.O.) \\ 2 Centro de Investigación en Materiales Avanzados (CIMAV), Departamento de Metalurgia e Integridad \\ Estructural, Miguel de Cervantes No. 120, Chihuahua 31109, Mexico; cynthiadeisy@gmail.com (C.G.E.); \\ roberto.martinez@cimav.edu.mx (R.M.S.) \\ 3 Departamento de Ciencias Básicas, Tecnológico Nacional de México, Campus Chihuahua II, Ave. de las \\ Industrias \#11101, Complejo Industrial Chihuahua, Chihuahua 31130, Mexico; \\ carmen.go@chihuahua2.tecnm.mx (C.G.O.); lucybeng12@gmail.com (L.E.L.B.) \\ * Correspondence: audelsantos@gmail.com
}

Citation: Santos Beltrán, A.; Gallegos Orozco, V.; Santos Beltrán, M.; Gómez Esparza, C.; Ronquillo Ornelas, I.; Gallegos Orozco, C.; Ledezma Beng, L..E.; Martínez Sánchez, R. Statistical and Microstructural Analyses of Al-C-Cu Composites Synthesized Using the State Solid Route. Materials 2021, 14, 1969. https://doi.org/ $10.3390 /$ ma14081969

Academic Editors: Luigi Solazzi and Andrea Spagnoli

Received: 30 January 2021

Accepted: 9 April 2021

Published: 14 April 2021

Publisher's Note: MDPI stays neutral with regard to jurisdictional claims in published maps and institutional affiliations.

Copyright: (c) 2021 by the authors. Licensee MDPI, Basel, Switzerland. This article is an open access article distributed under the terms and conditions of the Creative Commons Attribution (CC BY) license (https:// creativecommons.org/licenses/by/ $4.0 /)$.

\begin{abstract}
Aluminum powder with different $\mathrm{C}$ and $\mathrm{C}-\mathrm{Cu}$ mixtures powders were fabricated by powder metallurgy, using high-energy mechanical milling as a pre-treatment of powders. To evaluate the combined effect of the $\mathrm{C}-\mathrm{Cu}$ mixture and the process conditions, such as sintering temperature/time and milling time, on the yield stress and hardness, two experimental designs were carried out. The results were analyzed with Minitab Statistical Software using contour plots. From the results, better mechanical properties were found at a $\mathrm{Cu} / \mathrm{C}$ ratio of 0.33 and samples with high $\mathrm{C}$ content (3 wt. \%). In samples subject to long sintering time $(3 \mathrm{~h})$, the mechanism of precipitation of the second phase was mainly present, resulting in an improvement in mechanical properties. From the difference found between the elastic limit and the microhardness tests, it was found that there was an inefficient sintering process affecting the elastic limit test results. Additionally, $X$-ray analyses using the Rietveld program, were used for microstructural characterization and mechanical parameters of yield strength and ultimate tensile strength.
\end{abstract}

Keywords: Al-based composites; mechanical milling; nanoparticles dispersion

\section{Introduction}

Metal matrix composites (MMC) are characterized by having different properties that include high thermal resistance, low coefficient of thermal expansion, high specific resistance, sound damping capabilities, high resistance to corrosion, and high specific stiffness [1,2]. Ceramic-reinforced metal matrix composites are designed to combine the different mechanical properties of different materials to obtain a composite material for specific industrial applications. Some of the most used particles [3] that are used in the manufacture of $\mathrm{MMC}$ as reinforcements are silicon carbide $(\mathrm{SiC})$, aluminum oxide $\left(\mathrm{Al}_{2} \mathrm{O}_{3}\right)$, zirconia $\left(\mathrm{ZrO}_{2}\right)$, boron carbide $\left(\mathrm{B}_{4} \mathrm{C}\right)$, and graphite (Gram). Ajay R. Bhardwaj et al. [4,5] discussed various machinability aspects of MMC. Aluminum-based compounds have been manufactured using two main methods, solid state processing (e.g., powder metallurgy (PM) and mechanical alloying) and liquid state processing (e.g., stir casting). In the PM method, the matrix and the reinforcing material are mixed, compacted, and subsequently sintered to obtain a consistent material $[6,7]$. Mechanical alloying is the process in which a reinforcement is introduced into the metal matrix by means of high-energy mechanical milling of the powders to later compact and sinter them, this type of compound is known as dispersion-hardened materials [8,9]. Materials reinforced by dispersion of reinforcing particles belong to the group of composite materials that are manufactured mainly using 
powder metallurgy (PM) techniques. The convenience of manufacturing MMC using PM was compared with other manufacturing methods by Harris [10]. The manufacture of MMC via the liquid route has received much attention due to its low manufacturing cost, however, the main drawback was that the ceramic particles were randomly distributed and agglomerated during dendrite formation during solidification [11,12]. Using the PM method, it is possible to produce unique MMC materials with a very fine reinforcing particle distribution, which would otherwise be impossible to produce by conventional metallurgy in the liquid state. On the other hand, the methods of mechanical alloying (MA) and mechanical milling (MM) were widely used to produce high-performance materials, such as nanocrystalline materials, nanocomposites, intermetallic compounds, and amorphous materials $[13,14]$. MA facilitates alloy formation from elemental powders or refinement of pre-alloyed powder grains through high kinetic processing. This occurs due to the repeated welding and cold fracturing of the powders when the impact energy is transferred from the grinding media to the powders, until the stable state is obtained $[15,16]$. The final particle size (or crystallite) depends on the types of materials used (ductile or brittle), the initial particle size, and the processing conditions used during mechanical milling. Severe plastic deformation, repeated flattening, cold welding, and dust particle fracture during MA/MM lead to significant microstructure refinement, which is often accompanied by a transformation of metastable structures. The final powder produced by MA/MM can be further consolidated by standard powder metallurgy techniques used in the manufacture of bulk materials, or it can be deposited on the surfaces of engineered parts using various thermal spray methods. Some important studies have been carried out to determine the effectiveness of using $C$ as a reinforcing material in the aluminum matrix using mechanical milling [17-19]. During the sintering treatment, the content of $C$ dispersed in the aluminum matrix is transformed into the phase $\mathrm{Al}_{4} \mathrm{C}_{3}$, that substantially improves the mechanical properties of the compound [20,21]. Recently, special attention has been paid to $\mathrm{Al}-\mathrm{Al}_{4} \mathrm{C}_{3}$ composites. The homogeneous distribution of fine particles of $\mathrm{Al}_{4} \mathrm{C}_{3}$ act as obstacles for the dislocation movement, thus improving the yield stress of the Al matrix. Another important application of these materials is in the improvement of the dry sliding behavior due to residual carbon, which acts as a binder, in the matrix [22,23]. The aim of this study was to determine the combined effect of the $\mathrm{C}$ and $\mathrm{Cu}$ composition content and the processing conditions on the mechanical properties of the $\mathrm{Al}$ matrix by means of statistical analysis. Al-C-Cu composites were fabricated by combining the PM method and mechanical milling (MM) process.

\section{Materials and Methods}

The raw materials were $\mathrm{Al}$ powders (99.5\% purity, mesh -325) and pre-milled graphite with $\mathrm{Cu}$ as additive $(\mathrm{C}-\mathrm{Cu})$. Table 1 shows the compositions of metal-matrix composites studied for the first experimental design proposed to determine the effect of $\mathrm{C}$ and $\mathrm{Cu}$ content on the yield stress $\left(\sigma_{\mathrm{y}}\right)$ of composites. The table contains the Alp sample, and Alp with different $C$ contents $(0,0.375,0.75,1.5$, and 3 wt. \%) and different $\mathrm{Cu}$ contents $(0,0.5,1$, and $2 \mathrm{wt}$. \%). The additive $(\mathrm{C}-\mathrm{Cu})$ powders were milled for $4 \mathrm{~h}$, and the Al-C-Cu powders during $1 \mathrm{~h}$. Consolidated samples were sintered for $1 \mathrm{~h}$ at $550{ }^{\circ} \mathrm{C}$ under vacuum at a heating rate of $50{ }^{\circ} \mathrm{C} / \mathrm{min}$. Considering results found in the first experimental design, a second experimental design was established to determine the effect of different processing conditions on the mechanical properties of yield stress $\left(\sigma_{\mathrm{y}}\right)$ and microhardness (HV) of two composites with low and high C content, 0.75 and $3 \mathrm{wt}$. \% of $C$ respectively. For the experimental design, four sintering conditions process were considered: 1.5 and $3 \mathrm{~h}$ of sintering time and 500 and $600{ }^{\circ} \mathrm{C}$ of sintering temperature and four milling process conditions were considered: two for the additive powder $\mathrm{C}-\mathrm{Cu}$ ( 4 and $8 \mathrm{~h}$ of milling time) and two for the Al-C-Cu powder composition ( 1 and $4 \mathrm{~h}$ of milling time). All samples (from first and second experimental design) were mechanically processed in a high energy SPEX mill (Metuchen, NJ, USA) argon was used as the milling atmosphere. Devices and milling media used were made of hardened steel. The milling ball 
to powder weight ratio was 5:1 and the sample weight was $5 \mathrm{~g}$. For the additive $(\mathrm{C}-\mathrm{Cu})$, $1 \mathrm{mg}$ of methanol was used as process control agent and no process control agent was required for the $\mathrm{Al}-\mathrm{C}-\mathrm{Cu}$ composite fabrication. Consolidated products were obtained by pressing the milled powders for two minutes at $\approx 950 \mathrm{MPa}$ in uniaxial load. Consolidated samples were sintered under vacuum at a heating rate of $50{ }^{\circ} \mathrm{C} / \mathrm{min}$. Table 2 shows the nomenclature and composition used to fabricate the composite. Table 3 shows the second experimental design: temperature-time sintering and milling time conditions for the 75/25 and 3/100 composites. For the mechanical compression tests, the ratios height. Diameter of 1.0 was used according to the ASTM E9 standard. Using the statistics program "Minitab 17" (State College, PE, USA) (DC Montgomery, 2001), the combined effects of different experimental conditions on yield stress and microhardness were analyzed using contour graphs. To measure the relative density value, the Archimedes' technique was utilized. The crystallite size, lattice parameters and microstrain of the composites were obtained from the positions of the X-ray diffraction peaks calculated by the Rietveld method.

Table 1. Compositions for Al-C-Cu composites fabrication.

\begin{tabular}{ccccc}
\hline C (wt. \%) & \multicolumn{3}{c}{ Cu (wt. \%) } \\
\hline 0 & 0 & 0.5 & 1 & 2 \\
0.375 & 0 & 0.5 & 1 & 2 \\
0.75 & 0 & 0.5 & 1 & 2 \\
1.5 & 0 & 0.5 & 1 & 2 \\
3 & 0 & 0.5 & 1 & 2 \\
\hline
\end{tabular}

Table 2. Composition and identification of samples.

\begin{tabular}{cccc}
\hline & \multicolumn{3}{c}{ Composition (wt. \%) } \\
\hline Nomenclature & Al & C & Cu \\
\hline Alp & 100 & 0 & 0 \\
$75 / 0$ & 99.25 & 0.75 & 0 \\
$75 / 25$ & 99.0 & 0.75 & 0.25 \\
$75 / 50$ & 98.75 & 0.75 & 0.5 \\
$30 / 0$ & 97 & 3 & 0 \\
$30 / 100$ & 96 & 3 & 1 \\
$30 / 200$ & 95 & 3 & 2 \\
\hline
\end{tabular}

Table 3. Temperature-time sintering and milling time conditions for the 75/25 and 3/100 composites.

\begin{tabular}{cccc}
\hline $\begin{array}{c}\text { Milling Time (h) } \\
\text { C-Cu }\end{array}$ & $\begin{array}{c}\text { Milling Time (h) } \\
\text { Al-C-Cu }\end{array}$ & $\begin{array}{c}\text { Sintering Temperature } \\
\left({ }^{\circ} \mathbf{C}\right)\end{array}$ & $\begin{array}{c}\text { Sintering Time } \\
\text { (h) }\end{array}$ \\
\hline 4 & 1 & & \\
8 & 1 & 550 & \\
4 & 4 & & \\
8 & 4 & & \\
4 & 1 & 600 & \\
8 & 1 & & \\
4 & 4 & & \\
8 & 4 & 550 & \\
4 & 1 & & \\
8 & 1 & & \\
4 & 4 & & \\
8 & 4 & 600 & \\
4 & 1 & & \\
8 & 1 & & \\
4 & 4 & & \\
8 & 4 & & \\
\hline
\end{tabular}




\section{Results}

\subsection{Statistical Analysis}

The graph of Figure 1 a shows the effect of the $\mathrm{C}$ and $\mathrm{Cu}$ content on the yield stress $\left(\sigma_{\mathrm{y}}\right)$ of synthesized samples. It was observed that the samples that only contain $\mathrm{C}(0 \% \mathrm{Cu})$ had a significant increase in yield stress. With $3 \mathrm{wt}$. \% of C, the increase was around $208 \%$ of the Alp sample. On the other hand, for the samples containing only $\mathrm{Cu}$, the increase was around $33 \%$ with $1 \mathrm{wt}$. \% of $\mathrm{Cu}$, in respect to the Alp sample. The graph also shows an increase in the elastic limit with the $\mathrm{C}-\mathrm{Cu}$ content, however, a definite tendency of the elastic limit was not observed with the $\mathrm{C}-\mathrm{Cu}$ content. In order to determine if there was a combined effect of the $\mathrm{Cu}-\mathrm{C}$ mixture, the yield stress values were plotted with respect to the $\mathrm{Cu} / \mathrm{C}$ ratio. The Figure $1 \mathrm{~b}$ shows the graph $\mathrm{Cu} / \mathrm{C}$ ratio as a function of the yield stress $\left(\sigma_{\mathrm{y}}\right)$. The graph shows that each curve with different $C$ content presents a maximum yield stress value when the $\mathrm{Cu} / \mathrm{C}$ ratio corresponds to $0.333 \%$, followed by a noticeable decrease of the yield stress after this point. The composite sample with a $\mathrm{Cu} / \mathrm{C}$ ratio of $1 / 3$, produced an increase in yield stress value of $\approx 233 \%$, in respect to Alp sample.

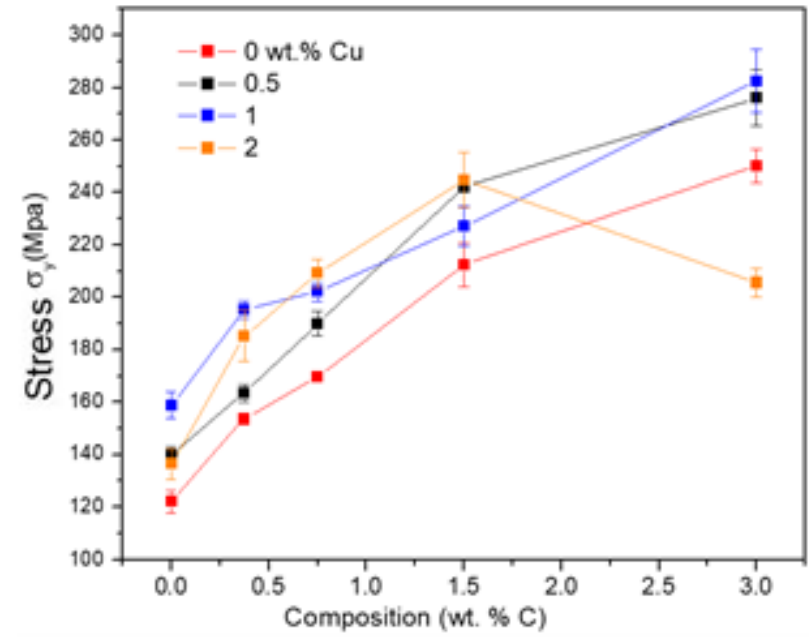

(a)

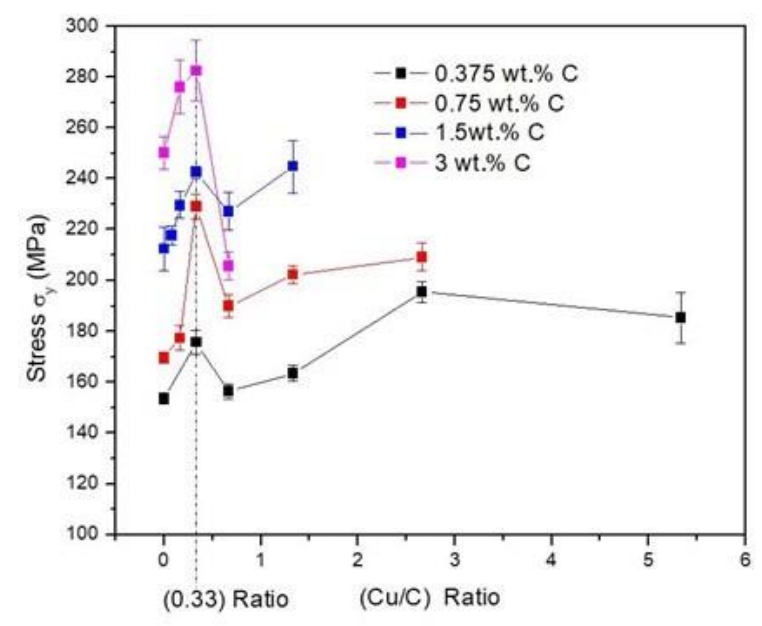

(b)

Figure 1. Yield stress $\left(\sigma_{\mathrm{y}}\right)$ as a function of composition: (a) as a function of $\mathrm{C}$ and at different $\mathrm{Cu}$ content; (b) as a function of the $\mathrm{Cu} / \mathrm{C}$ ratio and at different $\mathrm{C}$ content.

Figure $2 \mathrm{a}, \mathrm{b}$ show the results of yield stress $\left(\sigma_{\mathrm{y}}\right)$ and Vickers microhardness (HV) of the $3 / 100$ and $75 / 25$ samples. As observed, the yield stress and microhardness curves showed similar behavior with each experimental condition used. The 3/100 composites showed the best mechanical properties for each type of test, and the milling time for the synthesis of $\mathrm{C}-\mathrm{Cu}$ powder and the $\mathrm{Al}-\mathrm{C}-\mathrm{Cu}$ composites had the most significant effect on the mechanical properties. For the yield stress test, the best results found in the $3 / 100$ samples were at $4-4,1.5 \mathrm{~h}$, and $550{ }^{\circ} \mathrm{C}$ experimental conditions; and for the $75 / 25$ samples, the best results were at $4-4,3 \mathrm{~h}$, and $550{ }^{\circ} \mathrm{C}$ experimental conditions (see Figure 2a). In addition, an increase in the milling time in the $\mathrm{C}-\mathrm{Cu}$ additive powder from 4 to $8 \mathrm{~h}$ produced, in most of the samples $(3 / 100$ and $75 / 25)$, a decrease in the yield stress values. For the microhardness test, the best results found in the $3 / 100$ samples were at $8-4,1.5 \mathrm{~h}$, and $550{ }^{\circ} \mathrm{C}$ experimental conditions; and for the $75 / 25$ samples, were at $4-4$, $1.5 \mathrm{~h}$, and $550{ }^{\circ} \mathrm{C}$ experimental conditions (see Figure $2 \mathrm{~b}$ ). In the case of the $3 / 100$ samples, an increase in the milling time in the $\mathrm{C}-\mathrm{Cu}$ additive powder from 4 to $8 \mathrm{~h}$ produced an improvement in the microhardness results (see Figure $2 \mathrm{~b}$ ), except for the sample processed at $8-4,3 \mathrm{~h}$, and $600{ }^{\circ} \mathrm{C}$ experimental conditions. 


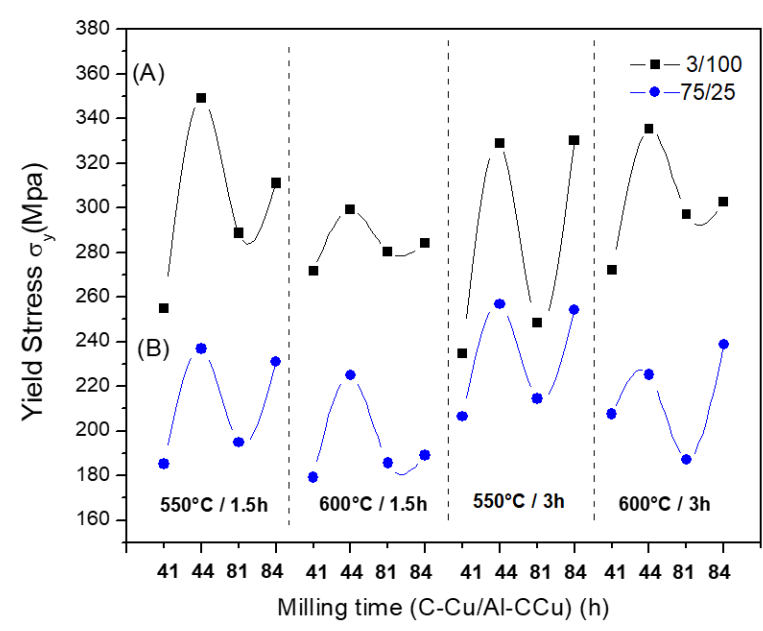

(a)

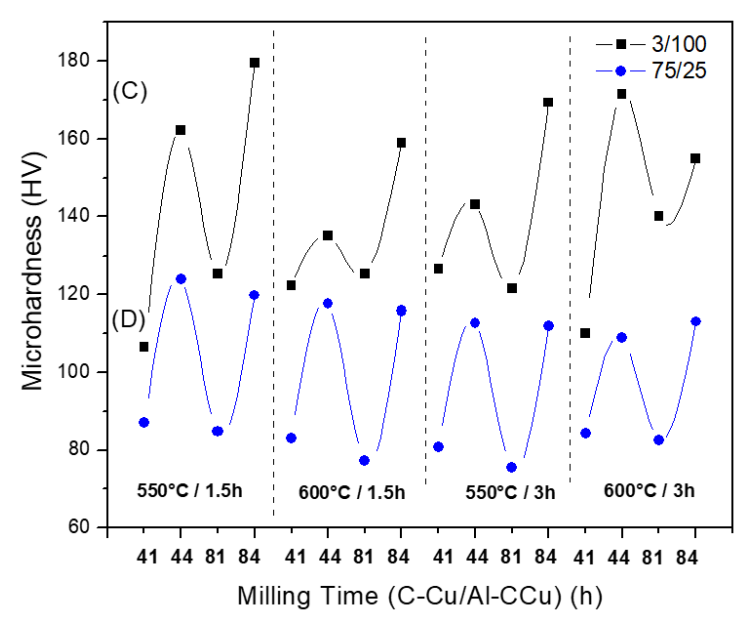

(b)

Figure 2. (a) Yield stress, $\sigma_{y}$, as a function of the composition and different processing conditions. (A) 3/100 samples. (B) $75 / 25$ samples. (b) Microhardness (Hv) as a function of the composition and different processing conditions. (C) (3/100) samples. (D) $75 / 25$ samples.

The yield stress $\left(\sigma_{\mathrm{y}}\right)$ and microhardness contour graphs for $75 / 25$ and $3 / 100$ composites are shown in the Figures 3 and 4 . For the case of the 75/25 composites (see Figure 3a), the maximum yield stress values that reached $\approx 250 \mathrm{MPa}$ were at a low temperature of sintering $\left(550^{\circ} \mathrm{C}\right)$ and $3 \mathrm{~h}$ of time of sintering. The contour graph also showed that the yield stress increased $\approx 6 \%$ when the sintering time changed from 1.5 to $3 \mathrm{~h}$ (at hold temperature of $550{ }^{\circ} \mathrm{C}$ ). On the other hand, the maximum microhardness values obtained of $\approx 123 \mathrm{HV}$ was at a low temperature of sintering $\left(550^{\circ} \mathrm{C}\right)$ and $1.5 \mathrm{~h}$ of sintering time (see Figure $3 \mathrm{~b}$ ). For the $3 / 100$ composites, the maximum yield stress value reached of $\approx 345 \mathrm{MPa}$ was at the low sintering temperature $\left(550^{\circ} \mathrm{C}\right.$ ) and $1.5 \mathrm{~h}$ of sintering time (see Figure $4 \mathrm{a}$ ). It is important to notice that the yield stress increased $\approx 10 \%$ when the sintering time changed from 1.5 to $3 \mathrm{~h}$ (at $600{ }^{\circ} \mathrm{C}$ hold). On the other hand, for the microhardness tests, a change in sintering temperature (from 550 to $600{ }^{\circ} \mathrm{C}$, at $3 \mathrm{~h}$ hold) produced an increase of $\approx 18 \%$ in the microhardness values (see Figure $4 \mathrm{~b}$ ). In addition, changing sintering time from 1.5 to $3 \mathrm{~h}\left(\right.$ at $600{ }^{\circ} \mathrm{C}$ ) produced an increase of $\approx 23 \%$ in microhardness values, with a maximum value obtained of about $170 \mathrm{HV}$.

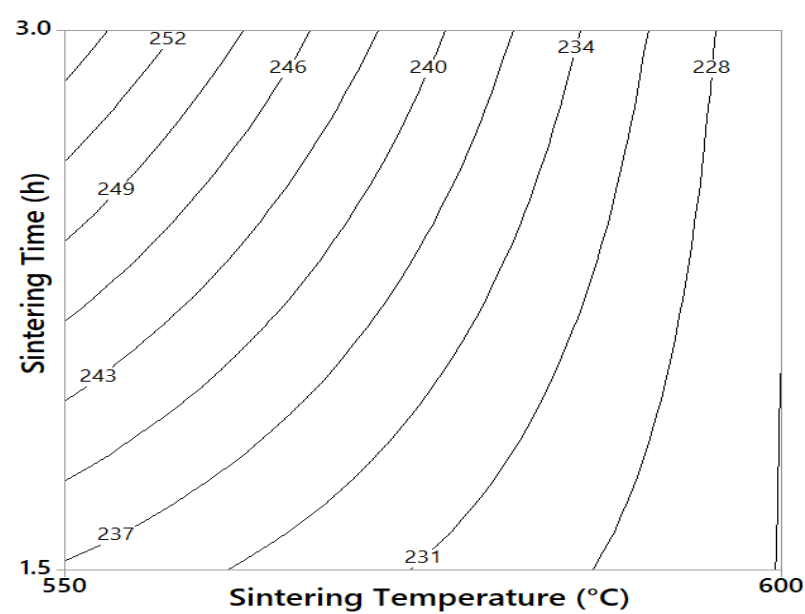

(a)

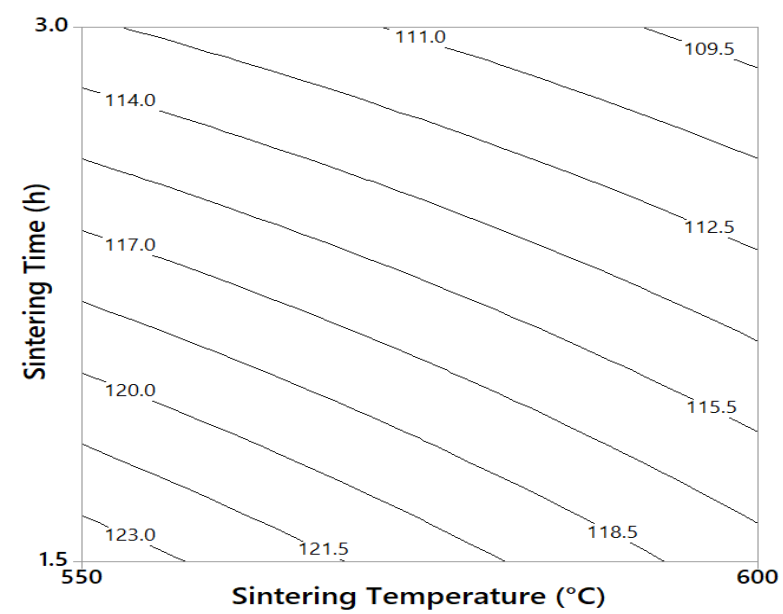

(b)

Figure 3. (a) Combined effect of time/temperature of sintering for the $75 / 25$ sample on the yield stress (at 4-4 hold conditions). (b) Combined effect of time/temperature of sintering for the 75/25 sample on the microhardness (at 4-4 hold conditions. 


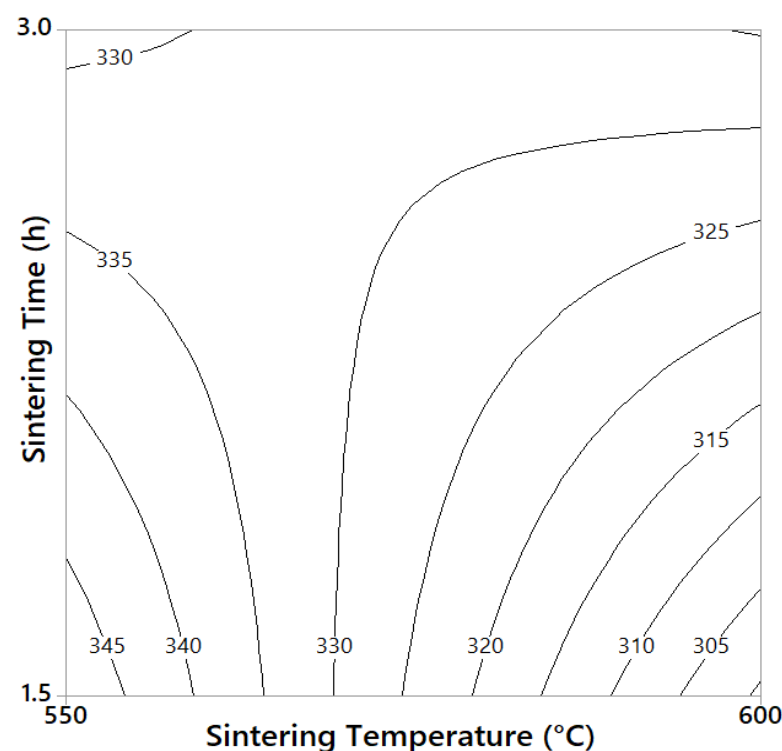

(a)

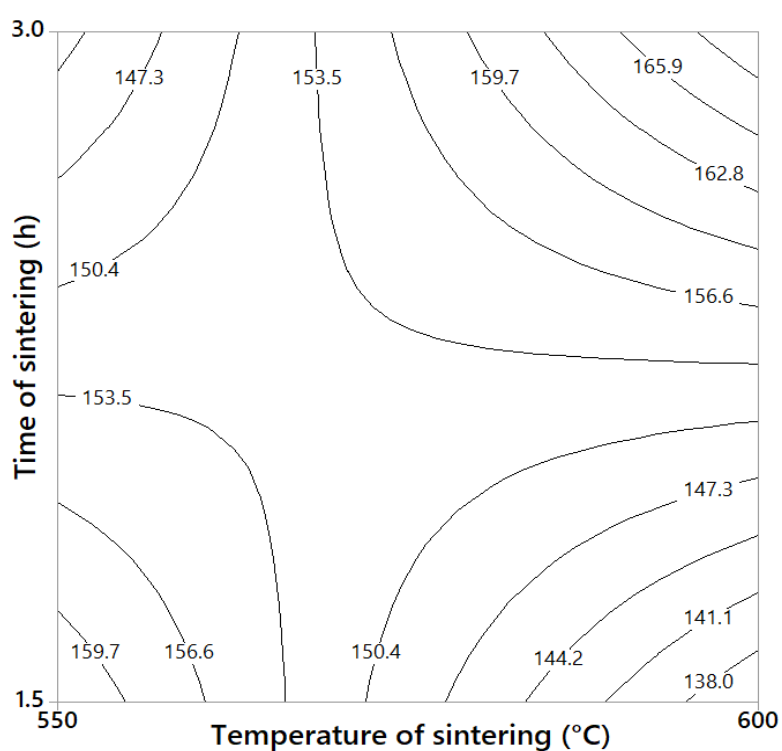

(b)

Figure 4. (a) Combined effect of time/temperature of sintering for the 3/100 samples on the yield stress (at 4-4 hold conditions). (b) Combined effect of time/temperature of sintering for the 3/100 sample on the microhardness (at 4-4 hold conditions).

The main rate of drop in mechanical properties with the temperature was also analyzed. For the $75 / 25$ sample, the elastic limit dropped faster $(\approx 10 \%)$ in samples subjected to a temperature change from 550 to $600{ }^{\circ} \mathrm{C}$ (at $3 \mathrm{~h}$ hold); while at $1.5 \mathrm{~h}$ time of sintering, the yield stress only dropped $\approx 4 \%$ (see Figure $3 \mathrm{a}$ ). On the other hand, for 3/100 samples, the yield stress dropped $\approx 13 \%$ when the temperature was increased from 550 to $600{ }^{\circ} \mathrm{C}$ (at $1.5 \mathrm{~h}$ hold), while in samples subjected at $3 \mathrm{~h}$ of sintering time, the change of sintering temperature produced practically no effect on the yield stress (see Figure $4 \mathrm{a}$ ). On the other hand, microhardness dropped $\approx 15 \%$ when $3 / 100$ samples were subjected to a sintering temperature change from 550 to $600{ }^{\circ} \mathrm{C}$ (at $1.5 \mathrm{~h}$ hold) and dropped $\approx 10 \%$ when samples were subjected a change in the time of sintering from 1.5 to $3 \mathrm{~h}$ (for samples sintered at $550{ }^{\circ} \mathrm{C}$ ), as observed in Figure $4 \mathrm{~b}$. The $75 / 25$ sample did not show a noticeable change in microhardness values with the change in temperature/sintering time process (see Figure 3b).

The results of the RD measurements for different compositions, milling times, sintering times, and temperature of sintering are indicated in the graph of Figure 5.

In general, the RD curves show similar behavior to that observed in the yield stress and microhardness results, but in the opposite direction. For both samples, 3/100 and 75/25, the combination 4-4 and 8-4 (at different temperature/time of sintering) processing conditions produced the lowest RD values. According to the results, powders with greater mechanical resistance show greater difficulty to be compacted in green, resulting in lower RD values. Samples with high $\mathrm{C}-\mathrm{Cu}$ content and with high milling time of processing showed greater mechanical resistance (as observed above) and reduced particle size. In addition to this, with a smaller particle size, the pores are smaller, and more pressure is required to collapse them [24]. Contour graphs were obtained using the "Minitab" program to know the effect of sintering temperature $\left(550\right.$ and $\left.600{ }^{\circ} \mathrm{C}\right)$ and sintering time $(1.5$ and $3 \mathrm{~h}$ ) on the relative density of the composites, using the 4-4 processing condition. The results are shown in Figure $6 \mathrm{a}, \mathrm{b}$ for the composites $75 / 25$ and 3/100, respectively. The highest rate of sintering was observed when the sintering time changed from 1.5 to $3 \mathrm{~h}$ (at $600{ }^{\circ} \mathrm{C}$ hold) for both samples, $75 / 25$ and 3/100. An increase in $\mathrm{RD}$ of $\approx 1 \%$ was observed in $75 / 25$ samples when the sintering time changed from 1.5 to $3 \mathrm{~h}$ (at $600{ }^{\circ} \mathrm{C}$ hold) as is appreciable in Figure $6 \mathrm{a}$, and about $2.2 \%$ for the $3 / 100$ sample under the same conditions (see Figure $6 \mathrm{~b}$ ). 


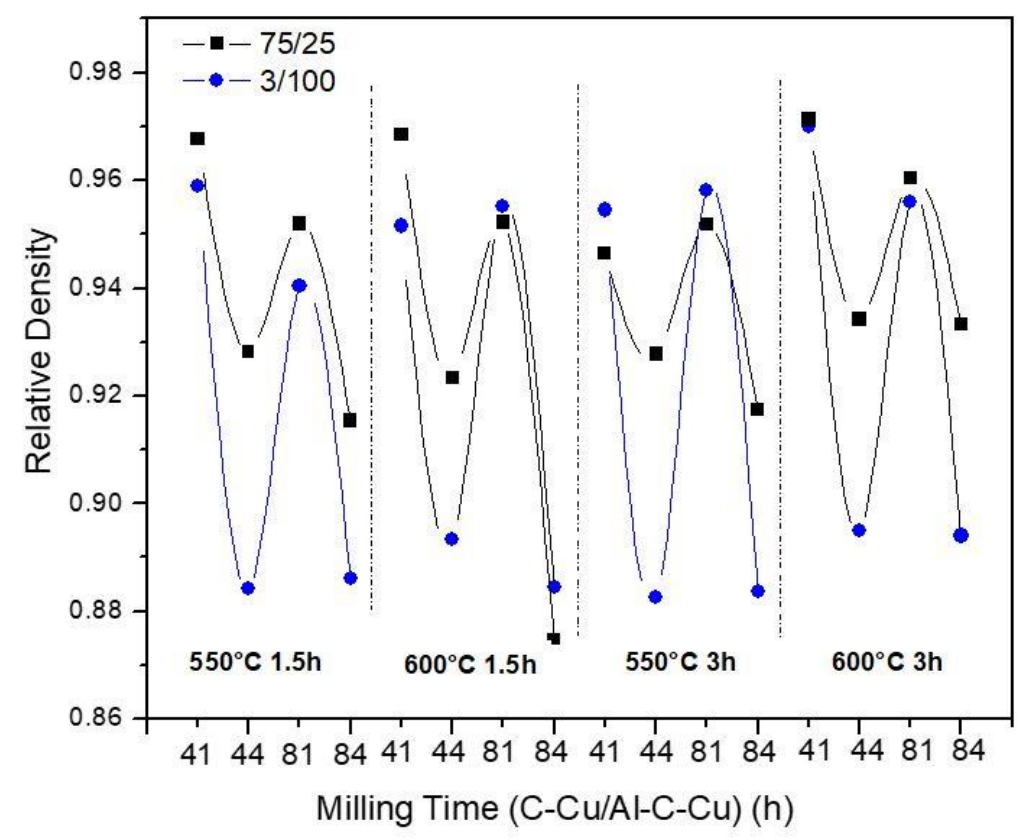

Figure 5. Relative density as a function of composition and processing conditions.

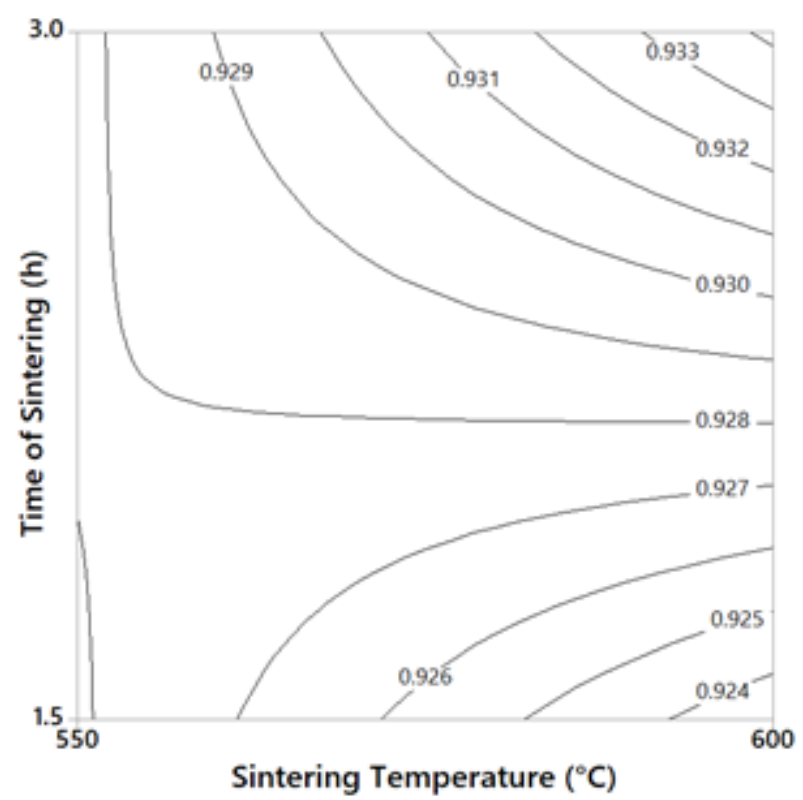

(a)

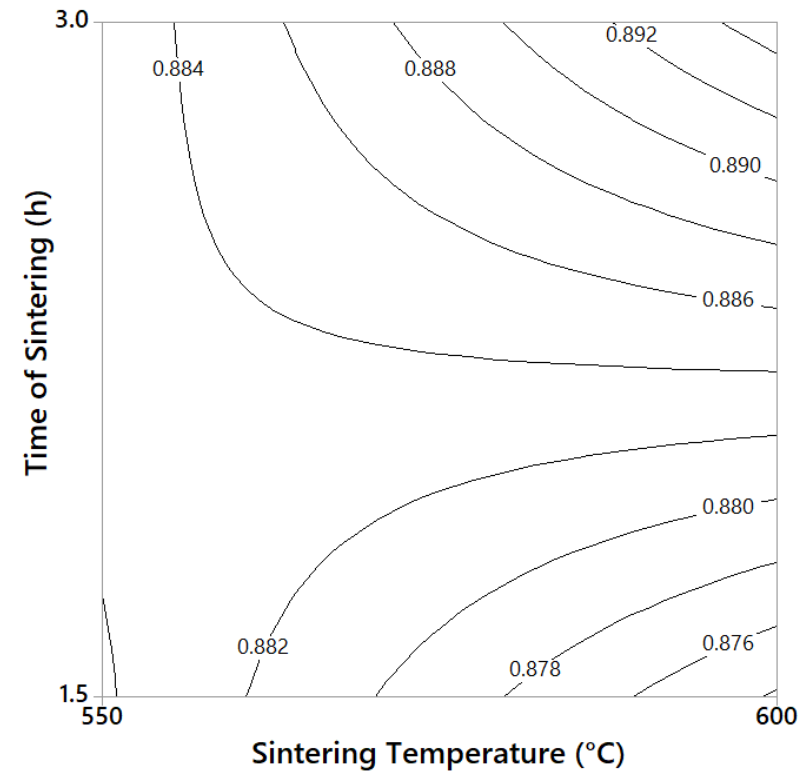

(b)

Figure 6. (a) Combined effect of time/temperature of sintering for the 75/25 samples on relative density (at 4-4 hold conditions). (b) Combined effect of time/temperature of sintering for the 3/100 samples on relative density (at 4-4 hold conditions).

\subsection{Microstructural Analysis}

Figure $7 \mathrm{a}, \mathrm{b}$ show the metallographic microstructure of $3 / 100$ and $75 / 25$ sample composites, the images show the microstructure and the particle size in the milled and compacted condition. As observed, the 3/100 sample showed a smaller particle size. 


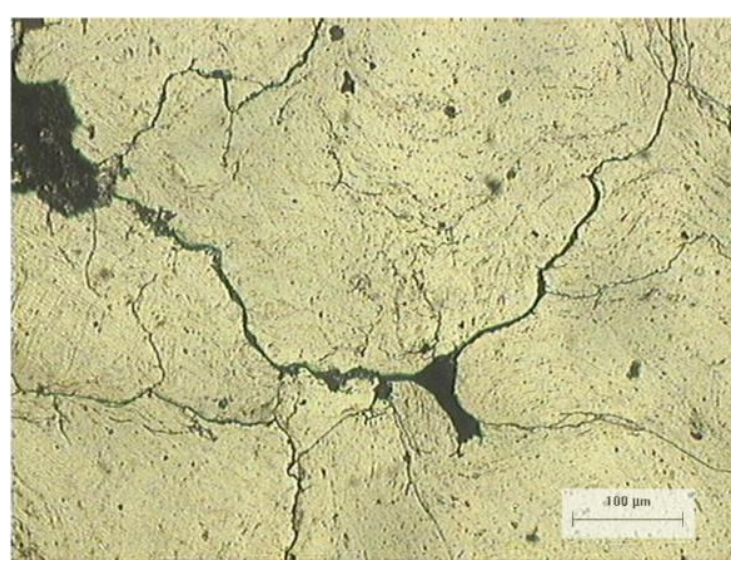

(a)

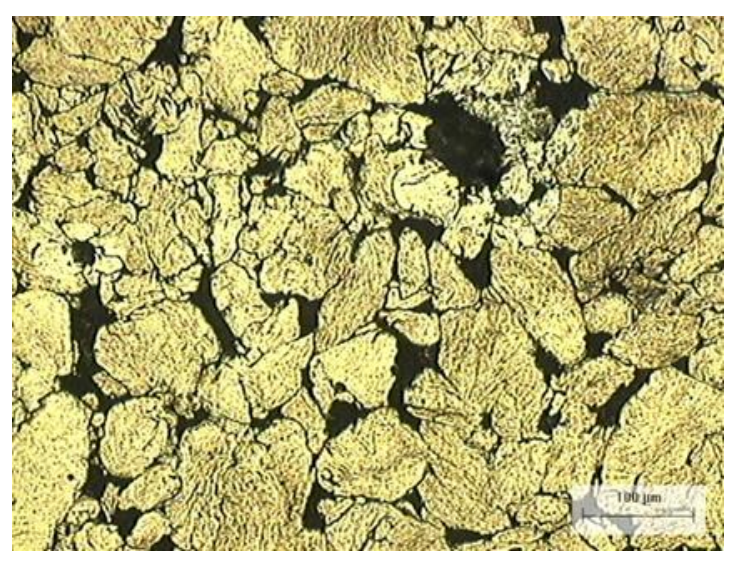

(b)

Figure 7. (a) Metallographic microstructure of the 75/25 composite. (b) Metallographic microstructure of the 3/100 composite.

The graphs of Figure 8a,b show the cumulative frequency distribution curves of the particle size for Alp and for compounds with 0.75 and $3 \% \mathrm{C}$, respectively, as a function of $\mathrm{Cu}$ content. The graphs indicate the position of the median, which corresponds to $50 \%$ of the cumulative percentage, while the standard deviation corresponds to 84 and $16 \%( \pm 1 \sigma)$ of the cumulative percentage. For the samples with $0.75 \% \mathrm{C}$, the particle size decreases with an increase of $\mathrm{Cu}$ content from 0.25 to $0.5 \mathrm{wt}$. \%. For the $75 / 25$ sample, $84 \%$ of the particles were below $150 \mu \mathrm{m}$ in size, while $80 \%$ of the particles were below $100 \mu \mathrm{m}$ in size for the 75/50 sample (see Figure 8a). On the other hand, for the composites with high C content ( $3 \mathrm{wt} . \%)$, a clear decrease in grain size was observed with the $\mathrm{C}$ content for the $3 / 0$ sample, and $\approx 84 \%$ of the grains were smaller than $50 \mu \mathrm{m}$ in size (see Figure $8 \mathrm{~b}$ ). Similar results were found for the $3 / 100$ sample $(\approx 84 \%$ of grains were $<50 \mu \mathrm{m})$, but in this case, unlike sample $3 / 0$, it was observed that the maximum particle size found was around $125 \mu \mathrm{m}$, and $200 \mu \mathrm{m}$ for the 3/0 sample. The 3/200 sample showed an evident increase of particle size, where approximately $84 \%$ of the particles were below $70 \mu \mathrm{m}$ and the maximum particle size found was around $250 \mu \mathrm{m}$.

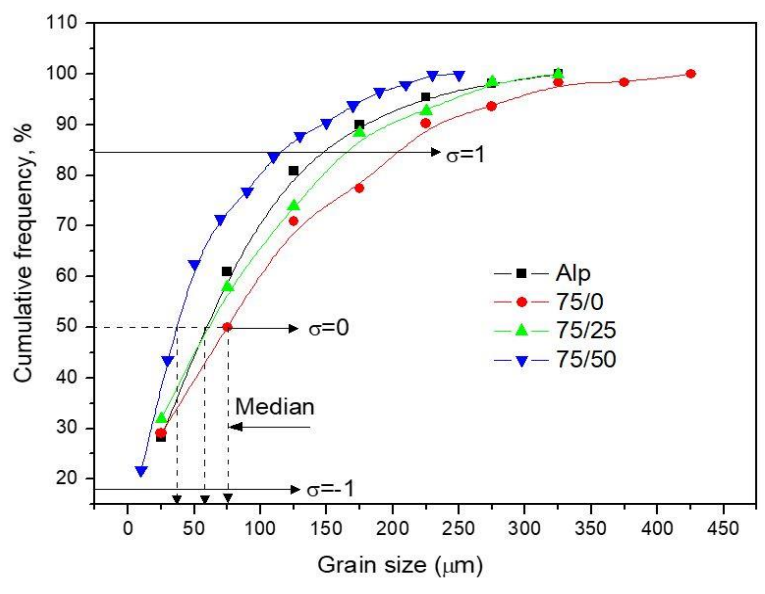

(a)

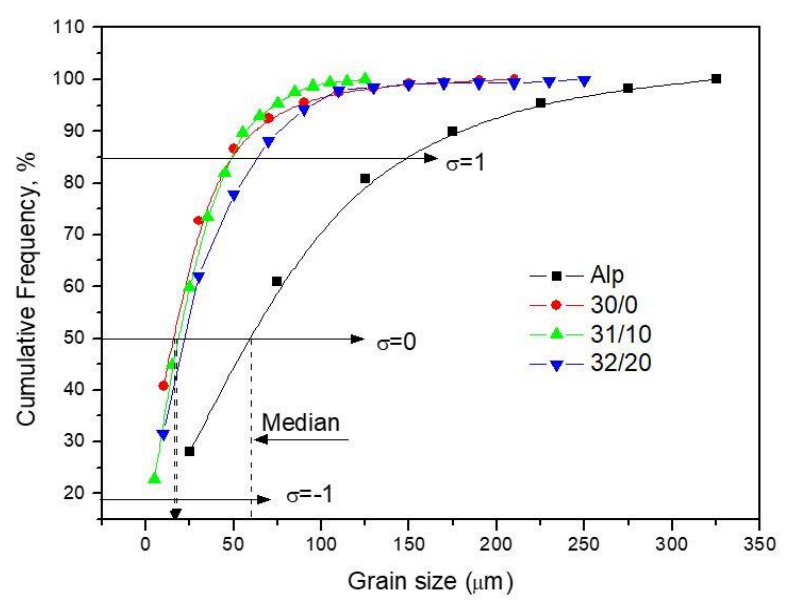

(b)

Figure 8. (a) Cumulative frequency curves of grain sizes for $75 / 25$ composites. (b) Cumulative frequency curves of grain sizes for $3 / 100$ composites.

\subsection{X-ray Diffraction Analysis}

Figure $9 \mathrm{a}, \mathrm{b}$ show the results of the X-ray diffraction analyzes of the samples with low and high $\mathrm{C}$ content, in the non-sintered state and the sintered samples respectively. 


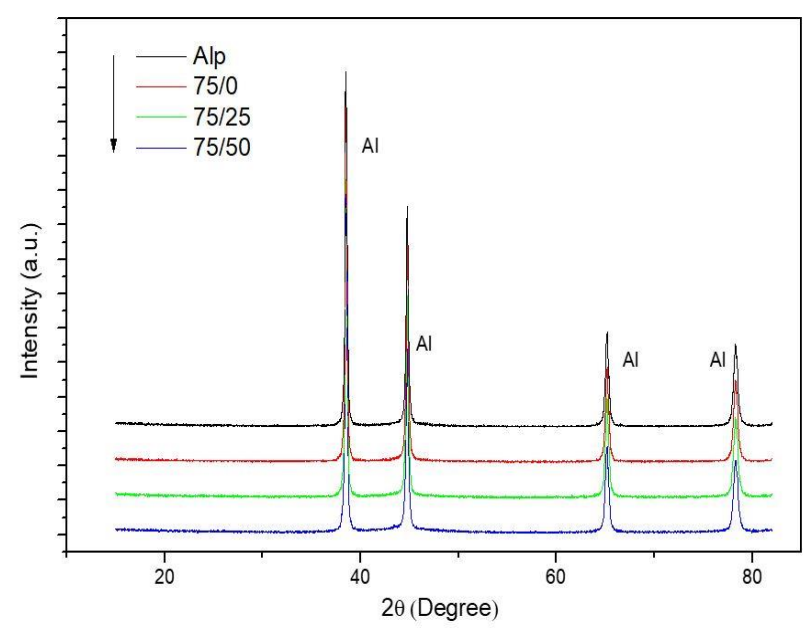

(a)

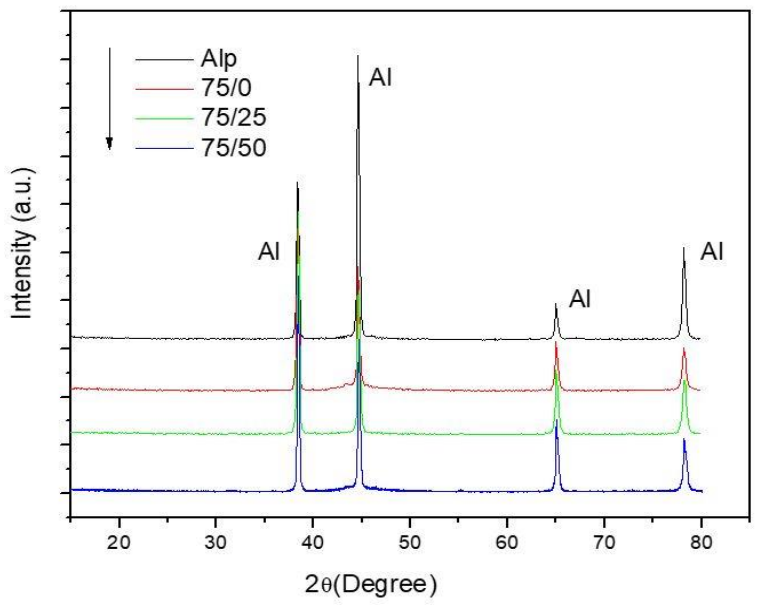

(b)

Figure 9. (a) X- ray diffraction profiles for the non-sintered composites with low $\mathrm{C}$ content. (b) X-ray diffraction profiles for the sintered composites with low $\mathrm{C}$ content.

Figure 10a shows the enlargement of X-ray diffraction profiles. In the patterns, it is appreciable the presence of the $\mathrm{Al}_{4} \mathrm{C}_{3}$ phase for the composites with $75 / 0,75 / 25$, and $75 / 50$ samples in the sintered condition. The best refinements of Rietveld fits obtained from the XRD standards, of the samples analyzed before the sintering process, were obtained when the crystallite size and the microstrain were considered as the main broadening effect of the peak. For the samples analyzed after the sintering process, it was when the microstrain was considered the main broadening effect of the peak. An example of Rietveld refinement of an XRD pattern for the sintered sample 75/0 was shown in Figure 10b.

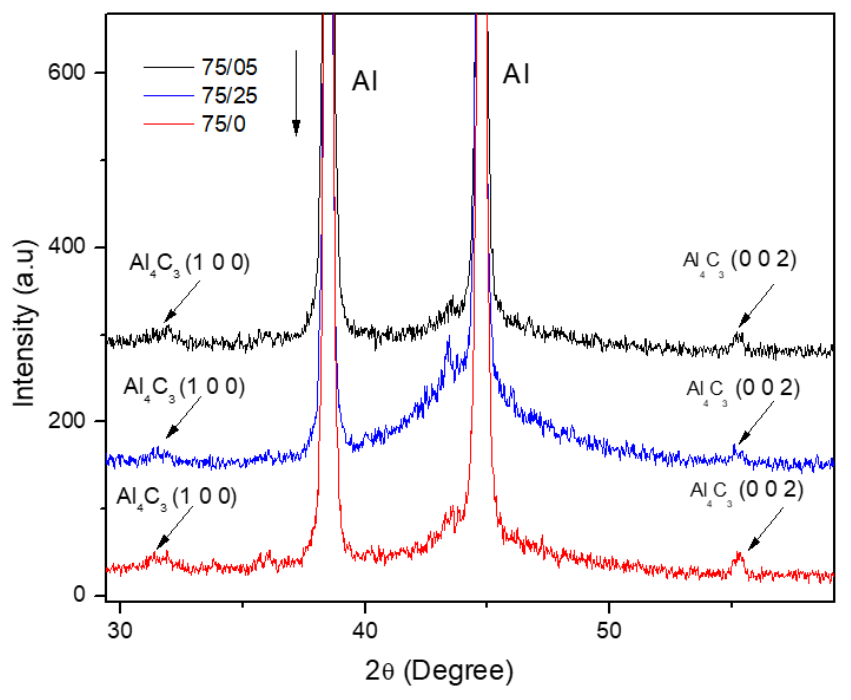

(a)

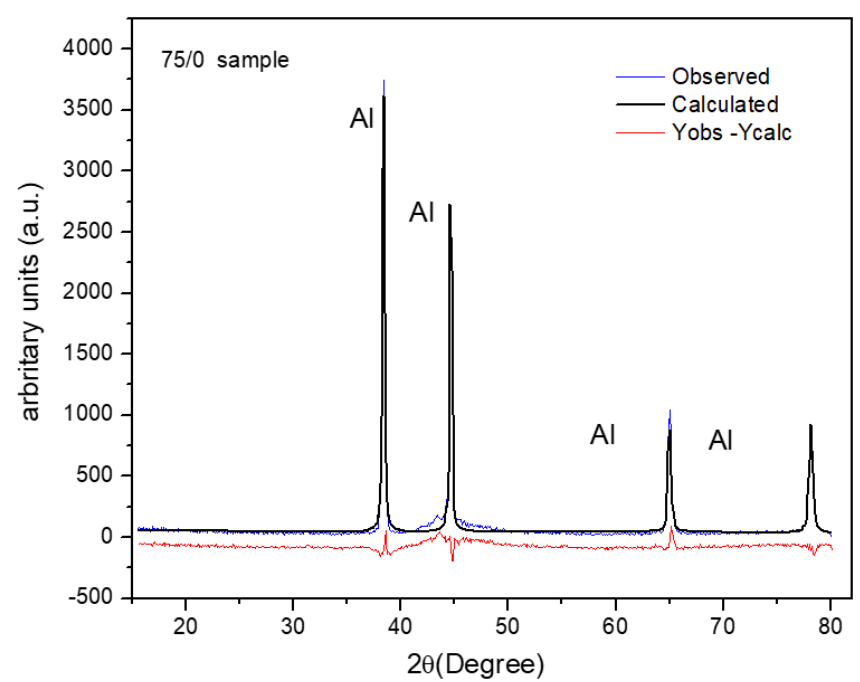

(b)

Figure 10. (a) Image enlargement of X-ray diffraction profiles of sintered samples. (b) The Rietveld refinement of the XRD pattern of the $75 / 0$ sintered sample.

Figure 11a,b show the crystallite size and microstrain from Rietveld refinement analysis. Figure 10a shows that crystallite size results as function of $C$, for low $C$ and high $\mathrm{C}$ content, in the non-sintered condition. As is observed in the graph, the Alp sample showed a reduced crystallite size $(\approx 70 \mathrm{~nm})$ as a product of the mechanical milling process. The addition of $0.75 \mathrm{wt}$. \% of $C$ content produced a greater decrease in the crystallite size of about $10 \%$. However, the addition of 0.25 wt. \% of $\mathrm{Cu}$ content (75/25 sample) resulted 
in a significant reduction in crystallite size of about $22 \%$ with respect to the Alp sample, and a greater decrease of about $33 \%$ with $0.5 \% \mathrm{Cu}$ was observed. These correlated well with grain size results found in metallography images, where the grain size also decreased with the $\mathrm{Cu}$ content (see Figure 8a). On the other hand, the addition of $3 \mathrm{wt}$. \% of $\mathrm{C}$ content to the $\mathrm{Al}$ matrix (see Figure 11a, high $\mathrm{C}$ content) produced a significant decrease in crystallite size of about $\approx 65 \%$ (with respect to the Alp), and the addition of $1 \mathrm{wt}$. \% of $\mathrm{Cu}$ content $(3 / 100$ sample) produced $\mathrm{a} \approx 55 \%$ decrease in crystallite size. However, for the sample with $2 \% \mathrm{Cu}$ content ( $3 / 200$ sample), the crystallite increased markedly, even above the value of pure aluminum $(\approx 85 \mathrm{~nm})$. Similar behavior was observed in grain size results found in metallography images (see Figure $8 b$ ), where the increase in the $\mathrm{Cu}$ content at $2 \mathrm{wt} . \%$ in $\mathrm{Cu}$ content resulted in an increase in grain size. Figure 10b shows the microstrains values results in the sintered and non-sintered condition, as a function of $C$ for low $C$ and high $C$ content. As observed in the graph, the Alp sample shows a relatively high microstrain value of $\approx 0.002$, a product of the mechanical milling process (see Figure 11a for low C content). The addition of $0.75 \mathrm{wt}$ \% of $C$ content produced an increase in the microstrain value of about $25 \%$, in respect to Alp sample; while adding 0.25 wt. \% of Cu content (75/25 sample) resulted in an increase of about $35 \%$, with respect to Alp sample. With a $0.5 \% \mathrm{Cu}(75 / 50$ sample), a slight decrease in value was obtained of about $30 \%$. After the sintering process, a similar decrease of microstrains values was observed for each sample, except for the sample 75/50 which shows a marked drop with the sintering process (from 0.0026 to 0.0013 ). For samples with high $C$ (see Figure 11b) content, all the samples show high microstrain values, about 0.0029 for $3 / 0$ sample before sintering and about 0.0025 after sintering. The microstrains values for $3 / 100$ and 3/200 were similar before and after sintering ( 0.0021 and 0.0025 , respectively).
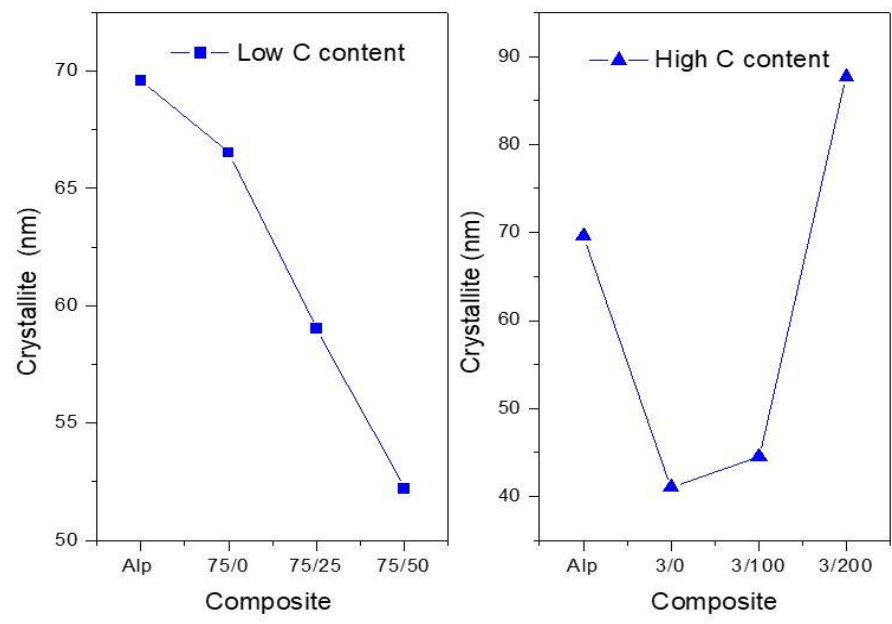

(a)
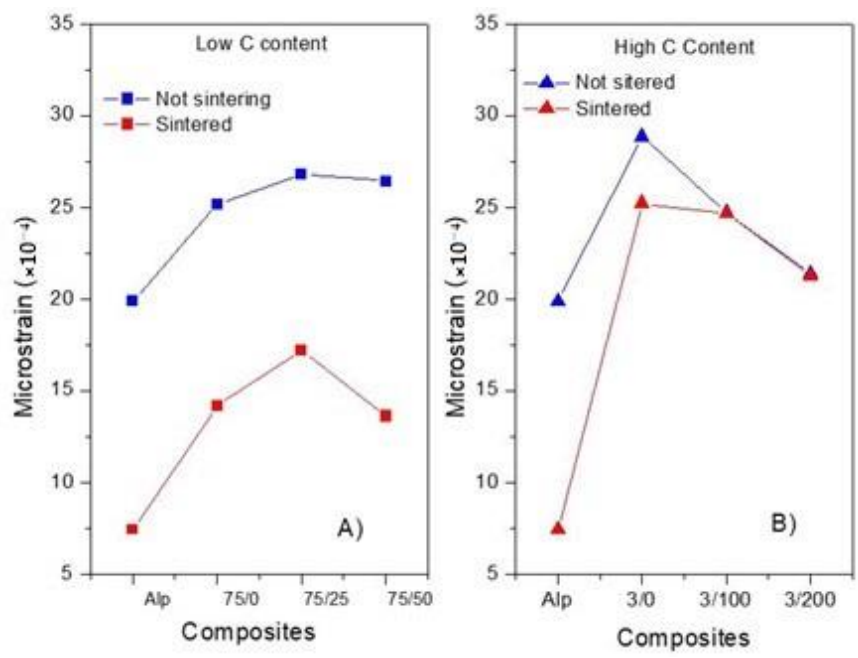

(b)

Figure 11. (a) Crystallite size for not sintered composites for high $C$ content and low $C$ content. (b) Microstrain values for not sintered and sintered composites, for high $\mathrm{C}$ and low $\mathrm{C}$ content.

\section{Discussion}

From the second experimental designs results, we observe that increasing the milling time in the fabrication of the Al-C-Cu compound powder from 1 to $4 \mathrm{~h}$ significantly increased both the yield stress and the microhardness of the composites. That is, for the $3 / 100$ samples fabricated at $1-4,1.5 \mathrm{~h}$, and $550^{\circ} \mathrm{C}$ experimental conditions, the yield stress was about $\approx 260 \mathrm{Mpa}$; while the samples fabricated at $4-4,1.5$, and $550{ }^{\circ} \mathrm{C}$ experimental conditions, a yield stress value of $\approx 360$ Mpa was reached (an increase of $\approx 138 \%$, in respect to the 1-4 experimental conditions). A similar behavior was observed in the microhardness test. The increase of the mechanical properties of the composite with the milling time is 
related to several strengthening mechanisms: grain size refinement, powder surface area increases, crystallite size reduction, integration and dispersion of the reinforcing particle into the $\mathrm{Al}$ matrix, and strain hardening, among others [25,26]. From the results, we observed that an increase in sintering temperature and time also favored the precipitation and growth of second phases (e.g., $\mathrm{Al}_{4} \mathrm{C}_{3}$ or $\mathrm{AlCu}$,); this effect was observed in the contour plot for the yield stress and microhardness tests when the sintering time was increased from 1.5 to $3 \mathrm{~h}$. The presence of these second phases has been previously reported in other works on X-ray diffraction analysis carried out on samples with $\mathrm{C}$ and $\mathrm{Cu}$ content $[27,28]$. The most significant effect was observed in the microhardness tests for $3 / 100$ samples, where a change in sintering change from 1.5 to $3 \mathrm{~h}$ (at $600{ }^{\circ} \mathrm{C}$ hold) resulted in an increase of approximately $\approx 23 \%$ in the microhardness value; while, for the yield stress tests (under the same conditions), it presented an increase of $\approx 10 \%$ (see Figure $4 a, b$ ). The difference between the yield stress and microhardness values obtained can be expected, because in the compression test, the resistance was obtained from the overall particle size of the compact and depends largely on the bond between the particles. In contrast, in microhardness tests, resistance was evaluated for a single particle of the composite powder. The degree of cohesion between adjacent particles strengthens with increasing temperature or sintering time, however, the increase in the yield stress was not proportional to that observed in the microhardness test. From this, it follows that what may be affecting the yield stress results is due to a poor sintering process. The difference between both tests was also observed in the $75 / 25$ samples, where the elastic limit increased $\approx 7.5 \%$ when the sintering time changed from 1.5 to $3 \mathrm{~h}$ (at $550{ }^{\circ} \mathrm{C}$ hold), while the microhardness values (subjected to under the same conditions) suffered a decrease of $\approx 9.5 \%$ (see Figure $3 a, b$ ). On the other hand, an increase in sintering time and temperature also favors recovery, recrystallization, and grain growth, which negatively affects the mechanical properties of the composite. For the $3 / 100$ samples, the yield stress dropped $\approx 13 \%$ in samples subjected to a change of sintering temperature from 550 to $600{ }^{\circ} \mathrm{C}$ (at $1.5 \mathrm{~h}$ hold), and microhardness dropped $\approx 15 \%$ subjected to the same conditions. In this sense, for samples sintered at high temperatures (at $600{ }^{\circ} \mathrm{C}$ ), the mechanism of recovery, recrystallization, and grain growth are mainly present; while for samples subject to long sintering time $(3 \mathrm{~h})$, the mechanism of precipitation of the second phase was mainly present, as stated above. The relative density results confirm the assumptions found above. An increase of $\approx 1$ and $2.2 \%$ in RD was found in $75 / 25$ and $3 / 100$ samples, respectively, when the sintering time changed from 1.5 to $3 \mathrm{~h}$ (at $600{ }^{\circ} \mathrm{C}$ hold), so that at high sintering time $(3 \mathrm{~h})$, the sintering process mechanism was strengthened. This result means that the yield stress results were affected by low cohesion between grains due to an inefficient sintering process, as observed above. This result may be related to the oxide layer on the Al particles, which prevents atomic mass transport during sintering. This undesirable effect during sintering was previously reported by Randall et al. [29], where the possible formation of oxide during sintering was established, which is greater, the greater the surface area of the powders. The presence of graphite distributed on the surface of compound powder particles during the milling process affecting the sintering process was reported previously [29,30]. It is important to note the phenomena presented above, as mechanism of recovery, recrystallization, grain growth, precipitation, etc, were faster in samples with high C content (3/100 samples), caused by a microstructure with a fine grain size and with high microstrain values, resulting in an accelerated diffusion mechanism. Other authors have reported that smaller particles tend to sinter at a higher rate due to the increased surface area [31]. From the microstructural results, it was observed that the $\mathrm{Cu}$ content had an important effect on the grain size. For a low content of $\mathrm{C}$, the grain size decreased as the content of $\mathrm{Cu}$ increased (see Figure 8a). However, for high $\mathrm{C}$ content composites, the grain size decreases only for a $\mathrm{Cu}$ content of $1 \mathrm{wt}$. \%, but for $2 \mathrm{wt}$ \%, the grain size increases markedly. The effect of the Cu content on the crystallite follows the same behavior (see Figure 11a) as that observed in the grain size analyzes shown in Figure 8a (for non-sintered samples). In general, at low C content, an increase in $\mathrm{Cu}$ content results in a decrease in grain size and crystallite size. On the 
other hand, for samples with high C content, an increase in $\mathrm{Cu}$ content $(>1 \mathrm{wt}$. \%) produces an increase in grain size and crystallite size. This behavior together with the microstrain results may explain the combined effect observed on the yield stress, where at $\mathrm{Cu} / \mathrm{C}$ ratio of $\approx 0.33$, a characteristic peak is observed. The analysis is as follows. The $75 / 25$ sample shows reduced crystallite size and relatively high microstrain values after the milling process and also high microstrain values after the sintering process (compared to the 75/50 sample). On the other hand, the $3 / 100$ sample shows a reduced crystallite size (if compared with the 3/100 sample) and relatively high microstrain values after the milling process and high microstrain values after the sintering process. This combination of reduced crystallite size and high microstrain values (after the sintering process) produced a high yield stress values for samples with $\mathrm{Cu} / \mathrm{C}$ ratio of $\approx 0.33$. On the contrary, for the sample with $2 \mathrm{wt}$. $\% \mathrm{Cu}$ content $(3 / 200)$, a relatively high value of crystallite was observed compared to the crystallite size of that of the $3 / 100$ sample after the milling process, which resulted in a low yield strength value. Additionally, it was observed that, the 3/200 sample also underwent a decrease in microstrain value after the sintering process, below the value of the sample of $3 / 100$.

\section{Conclusions}

From the first experimental design, the following conclusions were derived:

1. A characteristic peak was found in the yield stress test when the $\mathrm{Cu} / \mathrm{C}$ content ratio of $\approx 0.33$ was used to fabricate the composites. This increment of the yield stress was related to the microstructure of the composites after the milling and sintering process.

2. From the microstructural analyses, $3 / 100$ samples mainly showed a smaller crystallite size and a smaller and more homogeneous grain size. The 75/25 samples mainly showed a reduced crystallite size and relatively high microstrain values after the sintering process.

From a second experimental design, the following conclusions were derived:

1. From the contour plot, a significant difference between the microhardness and yield stress was found. From the contour plot analyses carried out on microhardness and yield stress, it was deduced that in the samples sintered at the higher temperature $\left(\right.$ at $\left.600{ }^{\circ} \mathrm{C}\right)$, the mechanism of recovery, recrystallization, and grain growth were mainly present, which resulted in a decrease in mechanical properties. On the other hand, in the samples subject to long sintering time $(3 \mathrm{~h})$, the mechanism of precipitation of second phase was mainly present, resulting in an improvement in mechanical properties.

2. From the difference found between the yield stress and microhardness, it was deduced that yield stress results were affected by low cohesion between grains due to a poor sintering process. These results were corroborated by the RD analyses, and were the best sintering processes that occurred at high sintering time $(3 \mathrm{~h})$ experimental condition. However, a small increase in RD was observed.

Author Contributions: Investigation, supervision, conceptualization, A.S.B.; methodology, validation, resources, V.G.O., resources, formal analysis, M.S.B.; validation, supervision, C.G.E., funding acquisition, software I.R.O.; software, methodology, C.G.O., writing original draft, conceptualization, L.E.L.B., investigation, methodology, R.M.S. All authors have read and agreed to the published version of the manuscript.

Funding: This research was funded by Universidad Tecnológica de Chihuahua Sur.

Institutional Review Board Statement: Not applicable.

Informed Consent Statement: Not applicable.

Data Availability Statement: Data sharing is not applicable for this article.

Conflicts of Interest: The authors declare no conflict of interest. 


\section{References}

1. Al-Maamari, A.E.; Iqbal, A.A.; Nuruzzaman, D.M. Mechanical and tribological characterization of self-lubricating Mg-SiC-Gr hybrid metal matrix composite (MMC) fabricated via mechanical alloying. J. Sci. Adv. Mater. Devices 2020, 5, 535-544. [CrossRef]

2. Shuvho, M.B.A.; Chowdhury, M.A.; Kchaou, M.; Rahman, A.; Islam, M.A. Surface characterization and mechanical behavior of aluminum based metal matrix composite reinforced with nano $\mathrm{Al}_{2} \mathrm{O}_{3}, \mathrm{SiC}, \mathrm{TiO}_{2}$ particles. Chem. Data Collect. 2020, $28,100442$. [CrossRef]

3. Kumar, A.; Singh, R.C.; Chaudhary, R. Recent progress in production of metal matrix composites by stir casting process: An overview. Mater. Today Proc. 2019, 12, 1453-1457. [CrossRef]

4. Ashwin Prabhu, G.; Muninathan, K.; Srinivasan, R.R.; Jayaganesan, S.; Kumar, M.A. Experimental Analysis of Al-359 reinforced with $\mathrm{B} 4 \mathrm{C}$ and $\mathrm{Al}_{2} \mathrm{O}_{3}$ composite. Mater. Sci. Eng. 2020, 923, 012014.

5. Frutos, E.; Sanguino, P.; Trindade, B. In-situ development of $\mathrm{Fe}_{3} \mathrm{C}$ and $\mathrm{TiC}$ reinforcements during the mechanosynthesis of $\mathrm{Cu}-$ 10Sn-15Ti/diamonds composite powders by high energy ball milling: Microstructural, thermal, and mechanical characterization. Int. J. Refract. Met. Hard Mater. 2020, 95, 105433. [CrossRef]

6. Hidalgo, A.A.; Frykholm, R.; Ebel, T.; Pyczak, F. Powder metallurgy strategies to improve properties and processing of titanium alloys: A review. Adv. Eng. Mater. 2017, 19, 1600743. [CrossRef]

7. Moravcik, I.; Kubicek, A.; Moravcikova-Gouvea, L.; Adam, O.; Kana, V.; Pouchly, V.; Zadera, A.; Dlouhy, I. The origins of high-entropy alloy contamination induced by mechanical alloying and sintering. Metals 2020, 10, 1186. [CrossRef]

8. Matvienko, O.; Daneyko, O.; Kovalevskaya, T. Mathematical modeling of plastic deformation of a tube from dispersion-hardened aluminum alloy in an inhomogeneous temperature field. Crystals 2020, 10, 1103. [CrossRef]

9. Xie, Q.; Lian, J.; Sidor, J.J.; Sun, F.; Yan, X.; Chen, C.; Liu, T.; Chen, W.; Yang, P.; An, K.; et al. Crystallographic orientation and spatially resolved damage in a dispersion-hardened Al alloy. Acta Mater. 2020, 193, 138-150. [CrossRef]

10. Harrys, B. Engineering Composite Materials; The Institute of Materials: London, UK, 1999; p. 194.

11. Zhang, Q.; Sun, D.; Pan, S.; Zhu, M. Microporosity formation and dendrite growth during solidification of aluminum alloys: Modeling and experiment. Int. J. Heat Mass Transf. 2020, 146, 118838. [CrossRef]

12. Derimow, N.; Clark, T.; Abbaschian, R. Solidification processing and cooling rate effects on hexagonal $\mathrm{Co}_{22} \mathrm{Cr}_{18} \mathrm{Cu}_{20} \mathrm{Mn}_{16} \mathrm{Ti}_{24}$ high-entropy alloys. Mater. Chem. Phys. 2020, 240, 122188. [CrossRef]

13. Enayati, M.H.; Mohamed, F.A. Application of mechanical alloying/milling for synthesis of nanocrystalline and amorphous materials. Int. Mater. Rev. 2014, 59, 394-416. [CrossRef]

14. Beltowska-Lehman, E.; Bigos, A.; Szczerba, M.J.; Janusz-Skuza, M.; Maj, L.; Debski, A.; Wiazania, G.; Kot, M. Heat treatment of ultrasonic electrodeposited $\mathrm{Ni}-\mathrm{W} / \mathrm{ZrO}_{2}$ nanocomposites. Surf. Coat. Technol. 2020, 393, 125779. [CrossRef]

15. Shpotyuk, O.; Bujňáková, Z.L.; Baláz, P.; Shpotyuk, Y.; Demchenko, P.; Balitska, V. Impact of grinding media on high-energy ball milling-driven amorphization in multiparticulate $\mathrm{As}_{4} \mathrm{~S}_{4} / \mathrm{ZnS} / \mathrm{Fe}_{3} \mathrm{O}_{4}$ nanocomposites. Adv. Powder Technol. 2020, 31, 3610-3617. [CrossRef]

16. Praveen, D.V.; Raju, D.R.; Raju, M.V.J. Optimization of machining parameters of wire-cut EDM on ceramic particles reinforced Al-metal matrix composites-A review. Mater. Today Proc. 2019, 23, 495-498. [CrossRef]

17. Zhang, J.; Liu, Q.; Yang, S.; Chen, Z.; Liu, Q.; Jiang, Z. Microstructural evolution of hybrid aluminum matrix composites reinforced with $\mathrm{SiC}$ nanoparticles and graphene/graphite prepared by powder metallurgy. Progress in Natural Science. Mater. Int. 2020, 30, 192-199.

18. Matvienko, Y.I.; Polishchuk, S.S.; Rud, A.D.; Popov, O.Y.; Demchenkov, S.A.; Fesenko, O.M. Effect of graphite additives on microstructure and mechanical properties of Al-Cu composites prepared by mechanical alloying and sintering. Mater. Chem. Phys. 2020, 254, 123437. [CrossRef]

19. Lim, C.; Gupta, M.; Ng, W.B. Friction and wear characteristics of Al-Cu/C composites synthesized using partial liquid phase casting process. Mater. Des. 1997, 18, 161-166. [CrossRef]

20. Mendoza-Duarte, J.M.; Estrada-Guel, I.; Carreño-Gallardo, C.; Martínez-Sánchez, R. Study of Al composites prepared by high-energy ball milling; effect of processing conditions. J. Alloy. Compd. 2015, 643, S172-S177. [CrossRef]

21. Estrada-Guel, I.; Carreño-Gallardo, C.; Cardoso-Cortés, J.L.; Rocha-Rangel, E.; Herrera-Ramírez, J.M.; Martínez-Sánchez, R. Effect of metallic addition on mechanical properties in an aluminum-graphite composite synthesized by means of mechanical milling. J. Alloy. Compd. 2010, 495, 403-407. [CrossRef]

22. Sharifi, E.; Enayatif, M.H.; Karimzadeh, F. Fabrication and characterization of $\mathrm{Al}_{-} \mathrm{Al}_{4} \mathrm{C}_{3}$ nanocomposite by mechanical alloying. Int. J. Mod. Phys. Conf. Ser. 2012, 5, 480-487. [CrossRef]

23. Arik, H.; Ozcatalbas, Y.; Turker, M. Dry sliding wear behavior of in situ $\mathrm{Al}-\mathrm{Al}_{4} \mathrm{C}_{3}$ metal matrix composite produced by mechanical alloying technique. Mater. Des. 2006, 27, 799-804. [CrossRef]

24. German, R.M. Shaping and Compaction. In Powder Metallurgy Science; Princeton Metal Powder Industries Federation: Princeton, NJ, USA, 1994; pp. 225-228.

25. Besterci, M. Preparation, microstructure and properties of Al-Al4C3 system produced by mechanical alloying. Mater. Des. 2006, 27, 416-421. [CrossRef]

26. Fogagnolo, J.B.; Velasco, F.; Robert, M.; Torralba, J.M. Effect of mechanical alloying on the morphology, microstructure and properties of aluminium matrix composite powders. Mater. Sci. Eng. 2003, 342, 131-143. [CrossRef] 
27. Santos-Beltrán, A.; Goytia-Reyes, R.; Morales-Rodriguez, H.; Gallegos-Orozco, V.; Santos-Beltrán, M.; Baldenebro-Lopez, F.; Martínez-Sánchez, R. Characterization of Al-Al4C3 nanocomposites produced by mechanical milling. Mater. Charact. 2015, 106, 368-374. [CrossRef]

28. Gallegos-Orozco, V.; Santos-Beltrán, A.; Santos-Beltrán, M.; Estrada-Guel, I.; Ronquillo-Ornelas, I.; Brito-Chaparro, J.; CarbajalSanchez, R. AFM Analyses of 3XXX series al alloy reinforced with dierent hard nanoparticles produced in liquid state. Materials 2020, 13, 272. [CrossRef] [PubMed]

29. Bostan, B.; Özdemir, A.T.; Kalkanli, A. Microstructure characteristics in Al-C system after mechanical alloying and high temperature treatment. Powder Metall. 2004, 47, 37-42. [CrossRef]

30. Son, H.T.; Kim, T.S.; Suryanarayana, C.; Chun, B.S. Homogeneous dispersion of graphite in a 6061aluminum alloy by ball milling. Mater. Sci. Eng. 2003, 348, 163-169. [CrossRef]

31. Chng, H.N.; Pan, J. Sintering of particles of different sizes. Acta Mater. 2007, 55, 813-824. [CrossRef] 